\title{
Malte Erik Wigand with Heinrich Ito (eds): Endoscopic Surgery of the Paranasal Sinuses and Anterior Skull Base
}

\author{
Hardcover (ISBN: 978-3-13-749402-7 Thieme)
}

\author{
Jens Lehmberg
}

Received: 10 September 2009 / Accepted: 11 September 2009/Published online: 6 October 2009

(C) Springer-Verlag 2009

This book is written for rhinologists by a master in endoscopic surgery of the paranasal sinuses. So, why should a neurosurgeon be interested in a book of ear, nose, and throat surgery? The answer may be as follows: since the endoscopic transnasal route in skull base surgery became quite popular among neurosurgeons in the last few years, neurosurgeons are more and more interested in the nose as natural orifice not only to profit from the benefits of the approach but also to control potential complications.

This second edition of the monograph was written by professor emeritus M. Wigand with the collaboration of H. Iro and seven more colleagues. Seventeen years after the first edition, content, and layout have been substantially revised. The hardcover is printed in letter format on qualitatively good paper. The originally English text uses popular, but not strictly correct terms to enhance the readability. The book comprises 13 chapters on 223 pages with 583 illustrations. The mix of drawings, operative and cadaver as well as patient photographs, radiologic images, and tables is very well balanced. With the amount of illustrations, this textbook could also represent an illustrated or operative atlas. The table of contents instantly shows coverage of all important aspects of endonasal surgery practiced by a rhinologist. The index is perfectly organized; each expression can be found easy and fast.

Starting to read the first chapter, the reader instantly learns what the book is about: pathophysiology of the nasal

J. Lehmberg $(\bowtie)$

Oberarzt der Klinik für Neurochirurgie, Klinikum rechts der Isar,

Technische Universität München,

Ismaninger Strasse 22,

81675 Munich, Germany

e-mail: Jens.Lehmberg@1rz.tu-muenchen.de mucosa and its operative restitution. After this jump into cold water, the author starts to go into detail. Anatomy, perioperative diagnosis, instrumentation, and anesthesia is followed by the different diseases, i.e., sinusitis - including complications and repeat surgery-and the adjuncts trauma, malformations, and neoplasias. Finally, the personal experience of the author in endoscopic sinus surgery and a historical overview is given. For a neurosurgeon, the title may be misleading. The book deals with the anterior skull base from below, and not in the neurosurgical view, commonly, from above. The chapters themselves are written in a narrative style with well-selected paragraphs. Highlighted boxes and take home massages are perfectly rare. One of the highlights of the book is the numerous illustrations. The author understands perfectly to guide the reader even through hard to interpret endoscopic images. All the images taken together are a parallel story to the text, facilitating to find a theme by thumbing through the book. At the end of each chapter, well-selected references and further readings are listed. The book is a statement of the authors' lifetime experience. But also the clinical differences with other experts in the field are discussed. Overall, the book is competitive with the few other books in this small, highly selective field.

The author states in his preface that at the time of publication of the first edition 17 years before, endoscopic sinus surgery was fairly new for the rhinologic community. The technique was partly welcomed but partly rejected by many as dangerous, if not hazardous, and as an insufficient solid method. Transnasal endoscopic neurosurgical interventions are at this stage nowadays. Perhaps with the aid of the broad experience displayed in this excellent book, skullbase surgeon will succeed in establishing endoscopy for interventions beyond the paranasal sinuses as superior and secure technique. 